\title{
Sistem Persuratan Digital Berbasis Virtual Private Network
}

\author{
Faizal $^{1}$, Andi Irmayana ${ }^{2}$ \\ ${ }^{1}$ Sistem Informasi, ${ }^{2}$ Teknik Informatika \\ 1,2Universitas Dipa Makassar \\ email: ichalabinurullah@gmail.com
}

\begin{abstract}
Problems regarding correspondence are experienced by government agencies, organizations and private companies where letters must be delivered directly and not necessarily received by the person concerned. In addition, the filing of incoming and outgoing mail is collected in a folder and stored in a filing cabinet. This can lead to several obstacles, such as ineffective distribution of letters, scattered letters, and untidy archiving so that the management of correspondence archives is not controlled. This study aims to design a digital correspondence to update the mailing system at the Karang Taruna South Sulawesi Province so that verification documents, organizational correspondence and information exchange between related agencies become more effective and secure by using Virtual Private Network (VPN) Technology. This study uses an experimental method by creating a system using the PHP programming language and MySQL database. This research is a qualitative research type, where the resulting system will be tested for specifications, both security specifications and functional specifications using black box testing methods. Virtual private network technology has been successfully applied to digital mail management and has been tested. The test results show that the entire system is in accordance with the test scenario for all functions on the system. The system built creates an attractive letter exchange facility that can be reached anywhere and anytime and maintains the confidentiality and security of documents for government agencies.
\end{abstract}

Keywords: Digital Correspondence, Virtual Private Network, Black Box.

Abstrak: Persoalan mengenai persuratan dialami oleh instansi pemerintah, organisasi dan perusahaan swasta dimana surat harus disampaikan secara langsung dan belum tentu diterima oleh orang yang bersangkutan. Selain itu, pengarsipan surat masuk dan surat keluar dikumpulkan dalam sebuah map dan disimpan dalam lemari arsip. Hal tersebut dapat menimbulkan beberapa kendala seperti pendistribusian surat yang tidak efekif, surat tercecer, dan pengarsipan yang tidak rapi sehingga manajemen arsip persuratan tidak terkontrol. Penelitian ini bertujuan merancang sebuah Persuratan digital untuk memperbaharui sistem persuratan pada Karang Taruna Provinsi Sulawesi Selatan agar dokumen verifikasi, persuratan organisasi dan pertukaran Informasi antar Instansi terkait menjadi lebih efektif dan aman dengan pemanfaatan Teknologi Virtual Private Network (VPN). Penelitian ini menggunakan metode eksperimen dengan membuat sebuah sistem menggunakan bahasa pemrograman php dan database MySQL. Penelitian ini berjenis penelitian kualitatif, dimana sistem yang dihasilkan akan diuji spesifikasinya, baik itu spesifikasi keamanan maupun spesifikasi fungsional menggunakan metode pengujian black box. Teknologi virtual private network berhasil diterapkan pada manajemen persuratan digital dan telah diuji. Hasil pengujian menunjukkan bahwa sistem seluruhnya telah sesuai dengan skenario pengujian untuk semua fungsi pada sistem. Sistem yang dibangun menciptakan fasilitas pertukaran surat yang menarik, dapat dijangkau dimanapun dan kapanpun serta menjaga kerahasiaan dan keamanan dokumen bagi instansi pemerintahan.

Kata kunci: Persuratan Digital, Virtual Private Network, Black Box.

\section{Pendahuluan}

Pesatnya kemajuan ilmu pengetahuan dan teknologi di Era Globalisasi menuntut masyarakat melakukan banyak perubahan. Hingga saat ini, surat menyurat di kantor-kantor atau instansi pemerintahan secara keseluruhan masih berjalan secara manual. Hal ini tidak diimbangi dengan intensitas persuratan yang makin tinggi 
dan menuntut kecepatan waktu. Terlebih lagi, kantor-kantor pemerintah perlu merencanakan ruangan dan perwakilan khusus untuk menyimpan surat dan melakukan pengumpulan informasi secara fisik. Mengingat bahwa semuanya dapat dilakukan secara modern, sistem pengiriman surat terkomputerisasi dalam organisasi saat ini penting untuk diterapkan di berbagai daerah perkotaan, tempat kerja, dan kantor-kantor pemerintah. Sistem persuratan digital dibuat untuk menangani dokumen organisasi, kantor dan instansi pemerintahan untuk menggunakan kertas seminimal mungkin dan mendigitalkan dokumen dengan teknologi yang tersedia. Pengelolaan surat secara manual masih dilakukan pada Karang Taruna Provinsi Sulawesi Selatan yang membukukan arsip surat masuk maupun surat keluar dalam suatu map yang ditumpuk dalam beberapa Lemari berkas sehingga data persuratan tidak terintegrasi dalam sebuah database dimana berpengaruh pada proses pembuatan laporan atau pencarian surat yang tidak efektif. Salah satu surat yang ditangani oleh Karang Taruna Provinsi adalah pengusulan peserta kegiatan yang akan diikutkan dalam kegiatan Diklat yang terkait dengan pertukaran informasi pada Karang Taruna Kabupaten Maros dan Karang Taruna Kabupaten Gowa.

Kemajuan teknologi merupakan kontributor yang tidak dapat dipisahkan untuk masalah tersebut sehingga sistem persuratan elektronik adalah jawaban yang dapat diterapkan pada kondisi ini. Beberapa penelitian telah menghasilkan sistem persuratan yang canggih, mengingat eksplorasi penting untuk administrasi suratmenyurat menjadi alasan pembuatan sistem persuratan yang terkomputerisasi sehingga kegiatan surat-menyurat antar SKPD dan siklus eksekusi dapat dilakukan dengan cepat. (Sibarani \& Negara, 2016). Sistem informasi kearsipan dinamis dimana semua responden mengakui bahwa fitur yang disediakan oleh SIKD telah memfasilitasi pekerjaan pegawai (Tjiptasari, 2018). Melalui Sistem informasi yang menangani dokumen arsip surat masuk dan surat keluar, proses pengarsipan surat yang terintegrasi antar bagian menjadi lebih mudah dan perlindungan surat melalui backup data apabila surat asli hilang atau rusak (Junus et al., 2018). Perancangan Labelling Pada Dokumen Menggunakan QR Code merupakan alternatif baru dalam pengamanan dokumen. Pengamanan pada dokumen ditunjang melalui penerapan public key infrastructure. Dimana, data/informasi mengenai dokumen tersebut telah dienkripsi terlebih dahulu dan diberi digital signature sebelum dienkripsi dengan QR Code (Pramihapsari \& Kaldera, 2012).

Perusahaan yang mempunyai kantor pusat dan kantor cabang tentunya membutuhkan koneksi khusus agar tidak terganggu oleh pengguna lain dan meminimalkan adanya serangan keamanan komputer dari luar, salah satu caranya adalah dengan menggunakan Virtual Private Network. Dari berbagai ternologi yang diterapkan pada penelitian yang telah disebutkan maka penulis mencoba membangun sistem persuratan digital dengan menerapkan ternologi virtual private network (VPN). Melalui teknologi tersebut dibuat jaringan bersifat "private" dan aman dengan menggunakan jaringan publik, misalnya internet. VPN adalah variasi jaringan komputer yang tingkatannya lebih advanced dibandingkan jaringan komputer biasa.

Virtual Private Network telah digunakan pada beberapa penelitian. Pengaksesan informasi dapat berlangsung lebih aman dan efektif dengan konsep Virtual Private Network dalam pengembangan jaringan komputer yang dimiliki. Dimana, beberapa fungsi utama untuk penggunaannya telah disediakan. Fungsi-fungsi utama tersebut antara lain : Confidentially (Kerahasiaan), Data 
Intergrity (Keutuhan data), Origin Authentication (Autentikasi sumber), Non-repudiation dan Kendali akses. Gambaran Remote Access VPN ditunjukkan pada gambar 1 (Pada \& Komputer, 2014).

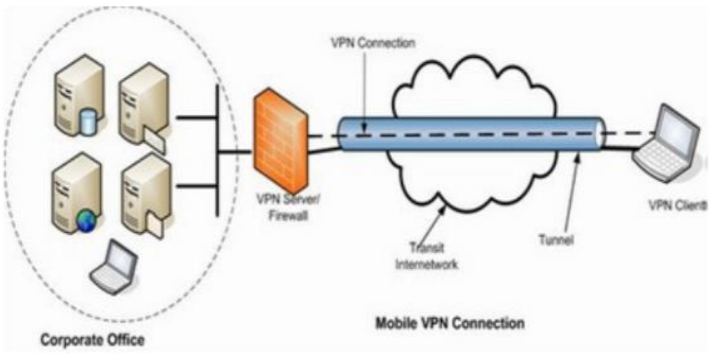

Gambar 1. Remote Access VPN

Pada Sistem Informasi Pengelolaan Keuangan Daerah Pemerintah Provinsi Riau, diharapkan rancangan infrastruktur jaringan nirkabel atau wireless yang meliputi perangkat keras dan perangkat lunak yang akan dibangun dapat menghubungkan atau menjembatani dua buah jaringan yang berbeda dan Membuat firewall. Untuk memaksimalkan kemananan jaringan diimplementasi teknologi Virtual Private Network (Saputra, 2016). Pembangunan Jaringan VPN untuk komunikasi lokal di Stmik Ppkia Pradnya Paramita Malang menggunakan metode Tunneling dan Mikrotik . Hasil pengujian komunikasi yang telah dilakukan adalah kedua user dapat berkomunikasi, yaitu dengan mengirim dan menerima pesan dari user satu ke user dua dan sebaliknya. Hasil pengujian tersebut telah berhasil membuat sebuah komunikasi menggunakan aplikasi Launch Tonic pada suatu jaringan local (Habibi \& Arifin, 2015). Penelitian tentang penerapan failover dengan memanfaatkan jaringan VPN dan Metronet di Astridogrup Indonesia. Dengan adanya penambahan koneksi menggunakan koneksi VPN, penting untuk mengubah konfigurasi sisi router, sehingga ketika koneksi utama khususnya koneksi Metronet Fiber Optic bermasalah, maka koneksi data akan berpindah menjadi koneksi VPN. Jika koneksi utama telah pulih, tentu saja koneksi akan beralih secara alami ke koneksi utama (Harsapranata, 2014). Penelitian yang menganalisis perbandingan penggunaan teknologi VPN pada PPTP dan L2TP. Dimana parameter QoS yang digunakan adalah throughput, delay, jitter, dan packet loss (Syariful Ikhwan, 2017).

Penelitian ini bertujuan Membangun suatu interface Sistem pengolahan surat digital berbasis web dan membangun sebuah database penyimpanan dokumen persuratan organisasi yang secara kualitas dan fungsionalnya akan diuji menggunakan metode pengujian black box, memanfaatkan Teknologi Virtual Private Network (VPN) yang mendukung sistem dalam menjaga kerahasiaan data dan keamanan dokumen.

Adapun beberapa batasan dalam penelitian antara lain :

1. Dokumen persuratan digital meliputi Surat Permintaan Peserta TKD, Surat Permintaan Peserta Pelatihan, Surat Penyampaian Kegiatan, Surat Tugas, Surat Undangan Memberikan Sambutan, Surat Undangan Menghadiri Kegiatan, Surat Permohonan Bantuan Dana, Surat Rekomendasi.

2. Distribusi persuratan digital terhadap seluruh kabupaten yang terdapat di provinsi Sulawesi Selatan dibatasi pada dua kabupaten yaitu Karang Taruna Kabupaten Maros dan Karang Taruna Kabupaten Gowa.

3. Implementasi Teknologi Virtual Network (VPN) akan disajikan dalam bentuk simulasi.

\section{Metode}

Penelitian ini dilakukan pada Kantor Sekretariat Karang Taruna Provinsi Sulawesi Selatan. Adapun perangkat keras yang dibutuhkan dalam penelitian antara lain berupa 3 buah komputer sebagai server-client, Harddisk kapasitas minimal 250 GB, memory kapasitas DDR3 1GB, perangkat lunak berupa web server AppServ, database MySQL, Web 
Browser chrome, LogMeIn sebagai penembak computer dan UML Star untuk desain konseptual.

Desain penelitian yang diterapkan untuk mengembangkan sistem Persuratan Digital menggunakan pendekatan pengembangan analisis dan perancangan sistem waterfall dengan pendekatan terstruktur:

1. Identifikasi Kebutuhan

pencarian kebutuhan ditingkatkan dan dipusatkan di sekitar pemrograman. Untuk mengetahui ide dari program yang akan dibuat. Identifikasi kebutuhan sistem dilakukan dengan cara mengadakan studi literature mengenai sistem persuratan digital dan teknologi Virtual.

2. Perancangan

Tahap ini digunakan untuk mengubah kebutuhan di atas menjadi gambaran sebagai rencana pemrograman sebelum pengkodean dimulai. Rencana tersebut harus memiliki opsi untuk mengeksekusi prasyarat yang dirujuk pada tahap sebelumnya. Seperti perancangan Use case system, activity diagram, sequence diagram, rancangan basis data dan rancangan antarmuka sistem.

3. Coding dan Implementasi

Agar dapat dimengerti oleh mesin, konfigurasi perancangan sistem harus diubah menjadi struktur yang dapat dimengerti oleh mesin, yaitu ke dalam bahasa pemrograman melalui proses coding. Sistem dibangun menggunakan bahasa pemograman PHP dan database MySQL.

4. Testing (Pengujian Sistem)

Metode pengujian Black Box digunakan untuk menguji fungsionalitas sistem yang dibangun. Dengan teknik pengujian tersebut, penguji tidak perlu memiliki pengetahuan tentang bahasa pemrograman tertentu karena pengujian dilakukan dari sudut pandang pengguna.
Ambiguitas atau inkonsistensi dapat diungkapkan dalam spesifikasi persyaratan programmer dan tester, keduanya saling bergantung satu sama lain.

Teknik pengumpulan data meliputi :

1. Studi Literatur, buku jaringan Komputer, pemrograman PHP dan MySQL, artikel-artikel dari internet dan literature penelitian terdahulu merupakan sarana dalam melakukan studi pustaka yang berkaitan dengan masalah yang dibahas.

2. Metode Pengambilan Data, dengan melakukan observasi dan wawancara langsung dengan pegawai Sekretariat Karang Taruna Provinsi Sulawesi Selatan terkait pendistribusian surat masuk ataupun surat keluar pada beberapa karang taruna kabupaten yang terdapat pada Provinsi Sulawesi Selatan

3. Metode Analisis Data, simulasi distribusi persuratan digital dengan pemanfaatan teknologi Virtual Private Network (VPN) mulai dari bagaimana surat digital itu dibuat, surat dikirim ke karang taruna Kabupaten, surat diterima oleh karang taruna provinsi hingga surat dicetak.

Pada Gambar 2 ditunjukkan Sistem persuratan digital di bangun ke dalam 3 buah server untuk tiga organisasi terkait dimana teknologi VPN dimanfaatkan agar kerahasiaan dan keamanan data dalam pendistribusian surat atau dokumen tetap terjaga. Karang Taruna Provinsi Sulawesi Selatan mengirimkan informasi keberhasilan Karang Taruna Kabupaten Maros dalam melaksakan kegiatan pelatihan di wilayahnya ke Karang Taruna Kabupaten Gowa. Karang Taruna Kabupaten Gowa mengirimkan surat permintaan ke Karang Taruna Provinsi Sulawesi Selatan untuk melakukan verifikasi 
awal ke anggota maupun pengurus organisasi untuk melaksakan kegiatan yang sama. Karang Taruna Kabupaten Gowa juga mengirimkan surat penyampaian ke Karang Taruna Kabupaten Maros sebagai penyelenggara kegiatan. Karang Taruna Kabupaten Maros mengirimkan persyaratan peserta yang berhak mengikuti Pelatihan ke Karang Taruna Kabupaten Gowa dan dilanjutkan ke Karang Taruna Provinsi Sulawesi Selatan. Karang Taruna Provinsi Sulawesi Selatan kemudian mengumpulkan dan mengirimkan data A1 untuk diinformasikan ke Karang Taruna Kabupaten Gowa dan Karang Taruna Kabupaten Maros untuk pelaksanaan Pelatihan. Setelah kegiatan pelatihan selesai, selanjutnya Karang Taruna Kabupaten Gowa Menginformasikan kelulusan Peserta yang mengikuti Pelatihan untuk mendapatkan sertifikat keahlian.

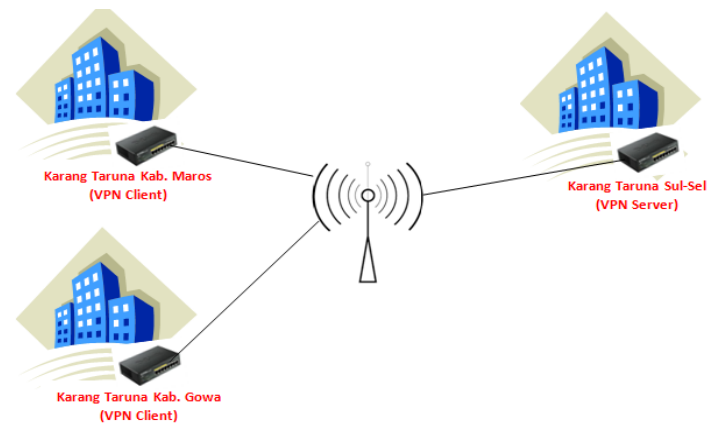

Gambar 2. Arsitektur kerja sistem dengan Teknologi VPN

Fungsional sistem secara umum akan diuji menggunakan teknik blackbox testing. Dengan teknik pengujian tersebut, struktur kontrol diperhatikan dengan tujuan agar perhatian berfokus pada domain informasi. Pengujian dirancang untuk menjawab pertanyaan sebagai berikut :

1. Bagaimana menguji validitas fungsional?

2. Kelas input apa yang membuat test case menjadi baik ?

3. Apakah sistem sangat sensitive terhadap nilai input tertentu ?
4. Bagaimana batasan dari suatu data dirahasiakan?

5. Sistem dapat mentolerir kecepatan data dan volume data apa saja?

6. Apa dampak kombinasi tertentu dari data terhadap operasi sistem ?

Spesifikasi system yang akan di uji meliputi :

a. Spesifikasi Keamanan dan Validasi

Tabel 1. Spesifikasi Keamanan dan Validasi

\begin{tabular}{|c|c|c|}
\hline No & Spesifikasi & Keterangan \\
\hline 1 & $\begin{array}{l}\text { Fungsi } \\
\text { Login }\end{array}$ & $\begin{array}{lr}\text { Fungsi } & \text { ini } \\
\text { diharuskan bagi } \\
\text { administrator untuk } \\
\text { melakukan } \\
\text { pembacaan dan } \\
\text { pegiriman surat }\end{array}$ \\
\hline 2 & $\begin{array}{l}\text { Fungsi } \\
\text { Validasi } \\
\text { Kesalahan } \\
\text { Password }\end{array}$ & $\begin{array}{lr}\text { Fungsi ini dibuat } \\
\text { untuk memastikan } \\
\text { password } r \text { yang } \\
\text { salah tidak } 37 y s t \\
\text { memasuki } 37 y \text { stem. }\end{array}$ \\
\hline 3 & $\begin{array}{l}\text { Fungsi } \\
\text { validasi } \\
\text { Pengiriman }\end{array}$ & $\begin{array}{l}\text { Fungsi ini untuk } \\
\text { memastikan Surat } \\
\text { tidak akan terkirim } \\
\text { sampai semua item } \\
\text { data telah terisi. }\end{array}$ \\
\hline
\end{tabular}

b. Spesifikasi Fungsional

Tabel 2. Spesifikasi Fungsional

\begin{tabular}{|c|c|c|}
\hline No & Spesifikasi & Keterangan \\
\hline 1 & $\begin{array}{l}\text { Fungsi } \\
\text { Kirim Surat }\end{array}$ & $\begin{array}{lr}\text { Fungsi } & \text { ini } \\
\text { digunakan untuk } \\
\text { membuat surat } \\
\text { yang akan dikirim } \\
\text { keinstansi lain }\end{array}$ \\
\hline 2 & $\begin{array}{l}\text { Fungsi } \\
\text { Surat } \\
\text { Masuk }\end{array}$ & $\begin{array}{l}\text { Fungsi untuk } \\
\text { membaca surat } \\
\text { masuk dari instansi } \\
\text { lain. }\end{array}$ \\
\hline 3 & $\begin{array}{l}\text { Fungsi } \\
\text { Surat } \\
\text { Keluar }\end{array}$ & $\begin{array}{lr}\text { Fungsi ini untuk } \\
\text { mengetahui data } \\
\text { surat keluar. }\end{array}$ \\
\hline 4 & $\begin{array}{l}\text { Fungsi Edit } \\
\text { Profil }\end{array}$ & $\begin{array}{lr}\text { Fungsi ini } & \text { untuk } \\
\text { mengubah } & \text { data } \\
\text { profil } & \text { Karang } \\
\text { Taruna } & \end{array}$ \\
\hline
\end{tabular}




\section{Hasil}

Untuk menggambarkan konseptual sistem yang telah diidentifikasi selama analisis sistem, maka dirancang konseptual sistem sebagai berikut :

Use Case System

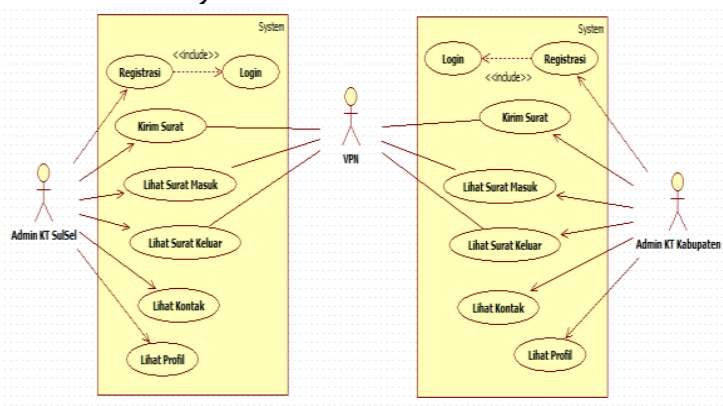

Gambar 3. Use Case System

Use case system yang ditunjukkan pada gambar 3 menggambarkan adanya dua system yang berdiri sendiri dan akan dikomunikasikan melalui beberapa actor diantaranya Admin pada Sistem dan VPN sebagai penghubung atar komunikasi data yang terjadi pada Karang Taruna Provinsi Sulawesi Selatan dan Karang Taruna Kabupaten sebagai contoh diantaranya Karang Taruna Kabupaten Maros dan Karang Taruna Kabupaten Gowa.

\section{Activity Diagram}

Activity diagram didasarkan pada sebuah atau beberapa case pada use case diagram. Hal ini bertujuan untuk memperlihatkan urutan aktifitas proses pada system.

a. Activity Diagram Login

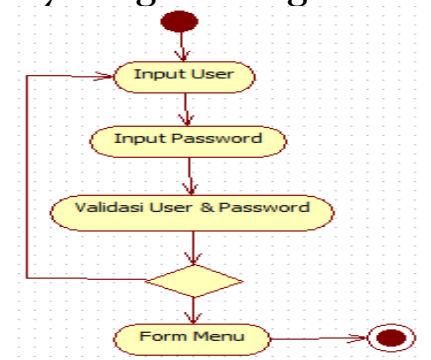

Gambar 4. Activity Diagram Login

Sebelum admin ataupun user masuk ke menu pilihan system, terlebih dahulu harus melakukan login ke sistem berdasarkan user dan password data yang telah dimasukkan saat registrasi. Urutan proses login hingga akhirnya menggunakan halaman menu ditunjukkan pada gambar 4. Selama user ataupun password tidak divalidasi oleh system maka pengguna tidak akan memperoleh hak akses terhadap system.

b. Activity Diagram Kotak Masuk

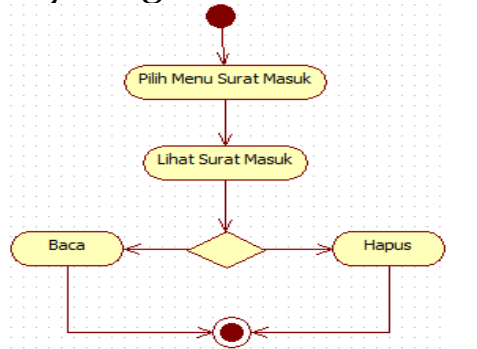

Gambar 5. Activity Diagram Kotak Masuk

Pada menu Surat Masuk seperti urutan aktifitas yang ditunjukkan pada gambar 5. pengguna dapat melihat Surat yang dikirimkan dari pihak luar yang terkait untuk selanjutnya dibaca ataupun dihapus.

\section{Sequence diagram}

Interaksi antar objek digambarkan didalam dan disekitar sistem berupa message yang digambarkan terhadap waktu. Sequence diagram terdiri atas dimensi vertikal (waktu) dan dimensi horizontal (objek-objek yang terkait). Pada gambar 6 ditunjukkan kolaborasi dinamis antara sejumlah objek untuk menggambarkan rangkaian pesan yang dikirim antara object juga interaksi antara object, sesuatu yang terjadi pada titik tertentu dalam eksekusi sistem.

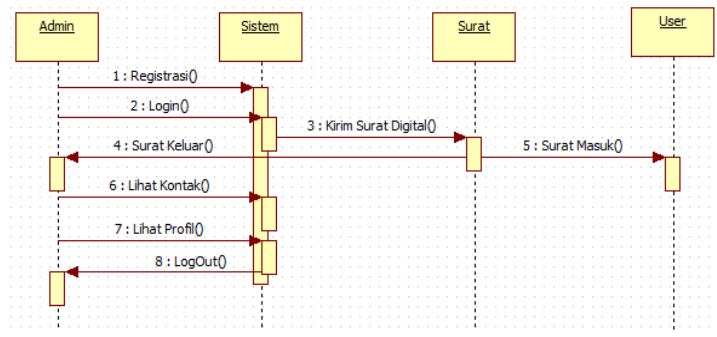

Gambar 6. Sequence Diagram 
Hubungan antar class dalam system ditunjukkan pada Gambar 7, dalam setiap class terdapat 3 area pokok utama yaitu nama, attribute dan operasi baik pada data user, kontak, berkas, surat masuk dan surat keluar.

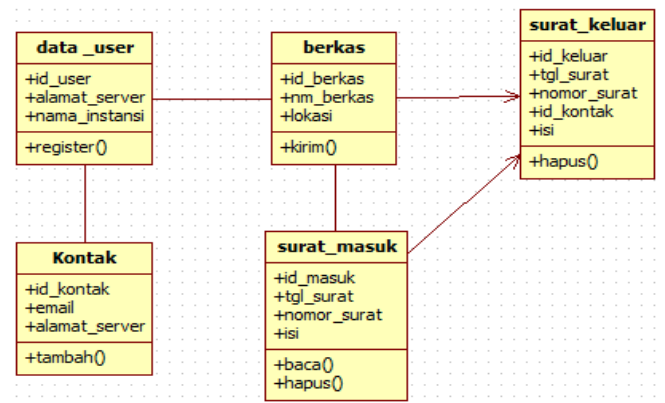

Gambar 7. Class Diagram Sistem

Sistem diimplementasikan dan dikoneksikan pada tiga sistem yakni pada 3 instansi pemerintahan yang terkait antara lain Sistem Informasi Persuratan Digital pada Karang Taruna Provinsi Sulawesi Selatan, Karang Taruna Kabupaten Maros, dan Karang Taruna Kabupaten Gowa. Pada sistem yang dibangun, peneliti membuat jaringan VPN pribadi menggunakan bantuan LogMeIn Hamachi. Dalam membangun hubungan secara langsung, antar-komputer yang terkoneksi ke dalam jaringan internet tidak memiliki konfigurasi yang rumit. Dengan kata lain, membentuk hubungan antar-komputer yang saling berjauhan melalui jaringan internet, seakan-akan komputer tersebut terhubung ke dalam jaringan lokal atau LAN, sehingga aplikasi / program dapat diakses bersama dari jarak jauh sebagaimana dalam sebuah LAN.

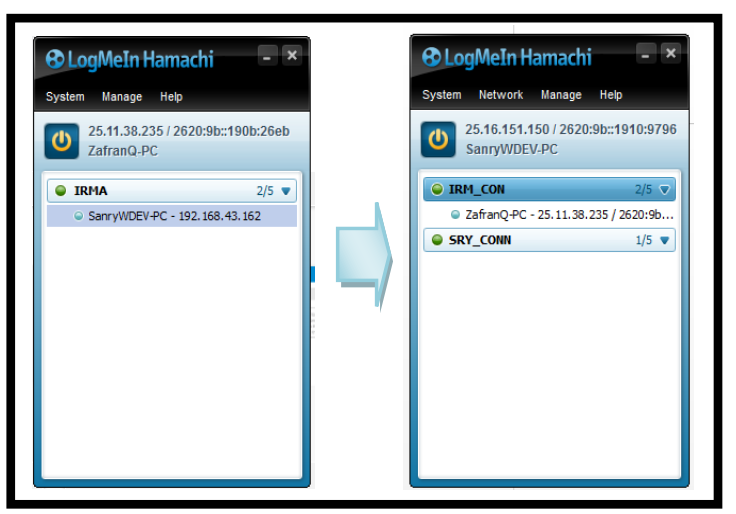

Gambar 8. Konfigurasi Jaringan
Gambar 8 menggambarkan konfigurasi jaringan sistem yang dibangun pada beberapa sistem dalam satu jaringan yang sama. Dari jaringan VPN yang dibangun, maka tiga sistem pada 3 instansi pemerintahan yang terkait dapat bertukar data dan informasi dengan aman. Notifikasi transaksi persuratan elektronik dari 3 sistem ditunjukkan pada gambar 9 .

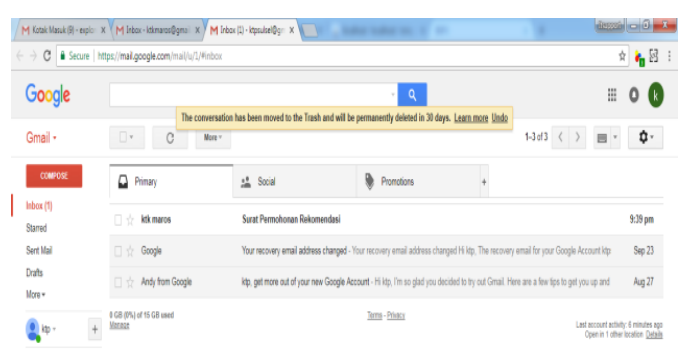

Gambar 9. Email Notifikasi

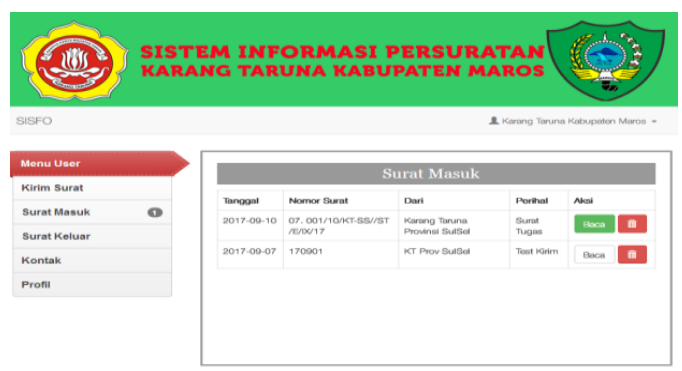

Gambar 10. Surat Masuk

Gambar 10 menunjukkan surat yang masuk atau surat yang dikirim pada suatu sistem akan terlihat pada menu surat masuk dan surat keluar. Contoh surat elektonik pada sistem terlihat seperti pada gambar 11 .

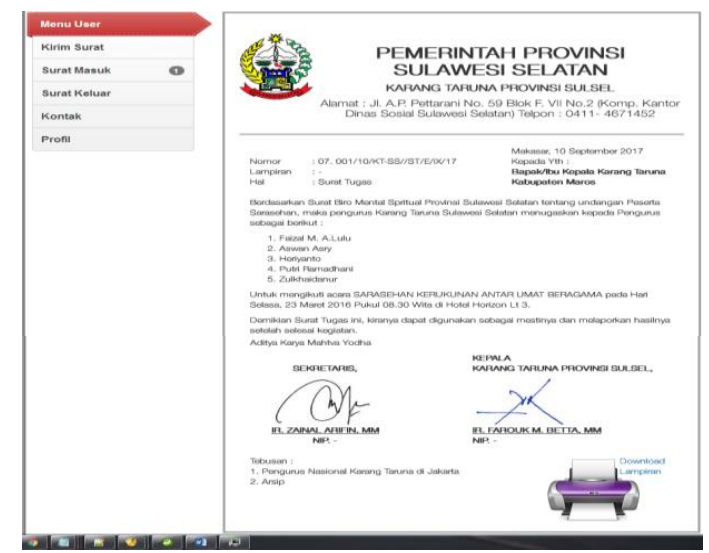

Gambar 11. Surat Tugas Elektronik 


\section{Pembahasan}

Berdasarkan pengujian sistem yang dilakukan menggunakan teknik pengujian black box dengan menguji fungsionalitas dari aplikasi, tombol dan kesesuaian sistem, maka diperoleh hasil pengujian sistem. Berdasarkan Hasil pengujian pada 22 skenario pengujian terhadap fungsi sistem menunjukkan sistem dapat berfungsi sesuai dengan harapan. Hasil pengujian ditunjukkan tabel 3 .

Tabel 3. Hasil Pengujian fungsional sistem

\begin{tabular}{|c|c|c|}
\hline Fungsi Sistem & Skenario Pengujian & $\begin{array}{l}\text { Hasil yang } \\
\text { diharapkan }\end{array}$ \\
\hline \multirow[t]{5}{*}{ Koneksi VPN } & $\begin{array}{l}\text { 1. Koneksi VPN Komputer Karang Taruna } \\
\text { Provinsi Sulawasi Selatan }\end{array}$ & Valid \\
\hline & $\begin{array}{l}\text { 2. Koneksi VPN Komputer Karang Taruna } \\
\text { Kabupaten Gowa }\end{array}$ & Valid \\
\hline & $\begin{array}{l}\text { 3. Koneksi VPN Komputer Karang Taruna } \\
\text { Kabupaten Maros }\end{array}$ & Valid \\
\hline & $\begin{array}{l}\text { 4. Koneksi VPN Komputer Karang Taruna } \\
\text { Provinsi Sulawesi Selatan dan VPN Komputer } \\
\text { Kabupaten Maros }\end{array}$ & Valid \\
\hline & $\begin{array}{l}\text { 5. Akses tiga Komputer jarak jauh dengan } \\
\text { aplikasi LogMeIn }\end{array}$ & Valid \\
\hline Registrasi & 6. Menyimpan Data Registrasi ke database sistem & Valid \\
\hline \multirow[t]{2}{*}{ Login Sistem } & 7. Validasi User dan password Sistem & Valid \\
\hline & $\begin{array}{l}\text { 8. Sistem menolak Validasi Jika user dan } \\
\text { password tidak sesuai Database }\end{array}$ & Valid \\
\hline Logout sistem & 9. Keluar dari sistem & Valid \\
\hline \multirow[t]{2}{*}{ Kirim Surat } & 10. Menyimpan data entry ke database & Valid \\
\hline & 11. Notifikasi email bahwa Surat berhasil dikirim & Valid \\
\hline \multirow[t]{5}{*}{ Surat Masuk } & 12. Notifikasi Surat Masuk & Valid \\
\hline & 13. Menampilkan Data Surat Masuk & Valid \\
\hline & 14. Surat Masuk dapat dibuka dan dibaca & Valid \\
\hline & 15. Surat Masuk dapat dicetak & Valid \\
\hline & 16. Surat Masuk dapat dihapus & Valid \\
\hline \multirow[t]{3}{*}{ Surat Keluar } & 17. Notifikasi Surat Keluar & Valid \\
\hline & 18. Menampilkan Data Surat Keluar & Valid \\
\hline & 19. Surat Keluar dapat dihapus & Valid \\
\hline Kontak & $\begin{array}{l}\text { 20. Menampilkan Data karang taruna kabupaten } \\
\text { yang berhasil registrasi }\end{array}$ & Valid \\
\hline Profil & $\begin{array}{l}\text { 21. Menampilkan data profil Karang Taruna } \\
\text { Provinsi Sulawesi Selatan }\end{array}$ & Valid \\
\hline Edit Profil & $\begin{array}{l}\text { 22. Dapat mengubah data profil Karang Taruna } \\
\text { Provinsi Sulawesi Selatan }\end{array}$ & Valid \\
\hline
\end{tabular}

\section{Simpulan}

Berdasarkan sistem yang telah dibangun dan diuji maka diperoleh kesimpulan Sistem informasi persuratan digital berhasil dibangun dengan interface yang menarik dapat digunakan dalam proses pertukaran surat dan dokumen penting antara karang taruna provinsi Sulawesi selatan dengan karang taruna tingkat kabupaten yang saling terkait. Menggunakan metode pengujian Blackbox, semua fungsi yang terdapat pada sistem telah diuji fungsionalnya dengan 22 skenario pengujian yang 
seluruhnya berhasil dan sesuai yang diharapkan. Sistem terhubung secara virtual dengan beberapa sistem yang terhubung secara privat sehingga pertukaran data dan informasi dapat dijamin keamanan dan kerahasiaannya. Dari hasil penelitian yang telah diperoleh, disarankan agar sistem ini dapat dipasang pada beberapa instansi dan lembaga pemerintahan dalam hal persuratan. Untuk penelitian selanjutnya, dapat ditingkatkan dengan teknologi yang lebih canggih.

\section{Daftar Pustaka}

Habibi, A., \& Arifin, S. (2015). Membangun Jaringan Virtual Private Network ( VPN ) Dengan Metode Tunneling Menggunakan Mikrotik Untuk Komunikasi Lokal di STMIK PPKIA Pradnya Paramita Malang. Jurnal Teknologi Informasi: Teori, Konsep Dan Implementasi, 6(2), 115-120.

Harsapranata, A. I. (2014). Implementasi Failover Menggunakan Jaringan VPN dan Metronet pada Astridogroup Indonesia. Creative Communication and Innovative Technology Journal, 8(2), 66-77.

Junus, M., Elektro, J. T., \& Malang, P. N. (2018). Sistem Informasi Pengelolaan Surat Masuk \& Surat Keluar Jurusan Teknik Elektro Berbasis Web Melalui Jaringan
Intranet Polinema. Jurnal Eltek, $16,18-32$.

Pada, D., \& Komputer, J. (2014). Kajian Virtual Private Network ( VPN ) Sebagai Sistem Pengamanan ( Studi Kasus Jaringan Komputer Unikom ). Majalah Ilmiah UNICOM, 12(1), 43-52.

Pramihapsari, M., \& Kaldera, M. P. (2012). Perancangan Labelling Pada Dokumen Menggunakan QR Code. Jurnal Teknik Komputer, 1, 59-67.

Saputra, D. (2016). Implementasi Virtual Private Network Pada Sistem Informasi Pengelolaan Keuangan. TEKNOLOGI, 6(2), 1831.

Sibarani, T. D. F., \& Negara, S.-I. A. (2016). Efektivitas Sistem Tata Persuratan Digital (e-Surat) di Dinas Komunikasi dan Informatika Kota Surabaya. Publika, 1104067401.

Syariful Ikhwan, A. A. (2017). Analisis Jaringan VPN Menggunakan PPTP dan L2TP. JURNAL INFOTEL, 9(3), 265-270.

Tjiptasari, F. (2018). Perceived usefulness ( persepsi kegunaan ) pengelolaan arsip digital menggunakan sistem informasi kearsipan dinamis ( SIKD ). Jurnal Kajian Informasi \& Perpustakaan, 5(2), 111-126. 